\title{
LONGITUDINAL DISPERSION PREDICTION OF RIVER BALOGUN USING CONSTANT DISTANCE AND TIME APPROACH AT DIFFERENT SAMPLING TIME INTERVALS
}

\author{
IMOKHAI T. TENEBE ${ }^{1}$, OGBIYE A. SAMUEL ${ }^{1}$, DAVID O. OMOLE ${ }^{1}$, PRAISEGOD C. EMENIKE ${ }^{1}$, \\ IREWOLE B. ONIEMAYIN ${ }^{1}$, DIWA I. DANIEL ${ }^{1}$ \& OMEJE MAXWELL ${ }^{2}$ \\ ${ }^{1}$ Department of Civil Engineering, Covenant University, Nigeria \\ ${ }^{2}$ Department of Physics, Covenant University, Nigeria
}

\begin{abstract}
The estimation of dispersion number or its coefficients can be used to determine the degradation capacity of rivers. This can be determined using tracer studies with the different methods found in the literature. However, for this study, the constant distance and time method was used at two different sampling time intervals to determine its value as well as the implication of being subjective in sampling time interval selection. This study showed that the dispersion number obtained from River Balogun using the Levenspiel and Smith approach at the 3 mins time interval $(\mathrm{d}=0.037152)$ and 5 mins interval $(\mathrm{d}=0.0214)$ varied by a factor of 1.76 . This implies that the dispersion number could be underestimated or overestimated. Furthermore, the first sampling interval required 1.54 times more tracer concentration data than the second sampling time interval thereby incurring more cost, time and labour. Therefore, it is suggested that more sustainable approaches are developed and practised that would use limited tracer data collection for calculation as well as limit subjectivity in sampling time selection, yet give closely precise values of dispersion number.
\end{abstract}

Keywords: river management, assimilatory capacity, dispersion coefficient, sustainable approach, pollution.

\section{INTRODUCTION}

Preventing pollution of water bodies would result in a better water quality, improved health for humans and aquatic species. However, when this is hampered, their existence will be under threat. With the EU bearing this in mind, a Water Framework Directive (WFD) in 2000 was designed to help chart this course [1], [2]. Even at that, it is herculean to find some of the rivers within the EU member states void of some form of effluent discharge. Therefore, it is important to understand the river dynamics as it relates to mixing and spreading, and this can be achieved by estimating the dispersion coefficient. There are various dispersion mechanism occurring during any form of accidental spill; however, the most predominant is the longitudinal dispersion (LD). According to [3], LD is useful to control biological, chemical and nuclear effluents discharged into rivers. Interestingly, the ID LD models sprung from Taylor in 1954, and more contributions were obtained from Fischer [4], [5]. Thereafter, even more models have evolved. Unfortunately, using these models for prediction do not produce accurate results of LD [7], [8]. Therefore, it is suggested that tracer studies remain one of the reliable methods for the determination of LD in channels, rivers or streams. This method involves the real-time collection of pollutant concentration at the same time or at different times with a section of the river. This pollutant concentration is usually in the form of a conservative tracer - salt tracers, like the one used in this study - and the dispersion coefficient is obtained using different equations and methods and these have been well reported by [9]. However, from the literature search, the various methods implored by various researchers include variable-time constant distance method, variable-time variable distance 

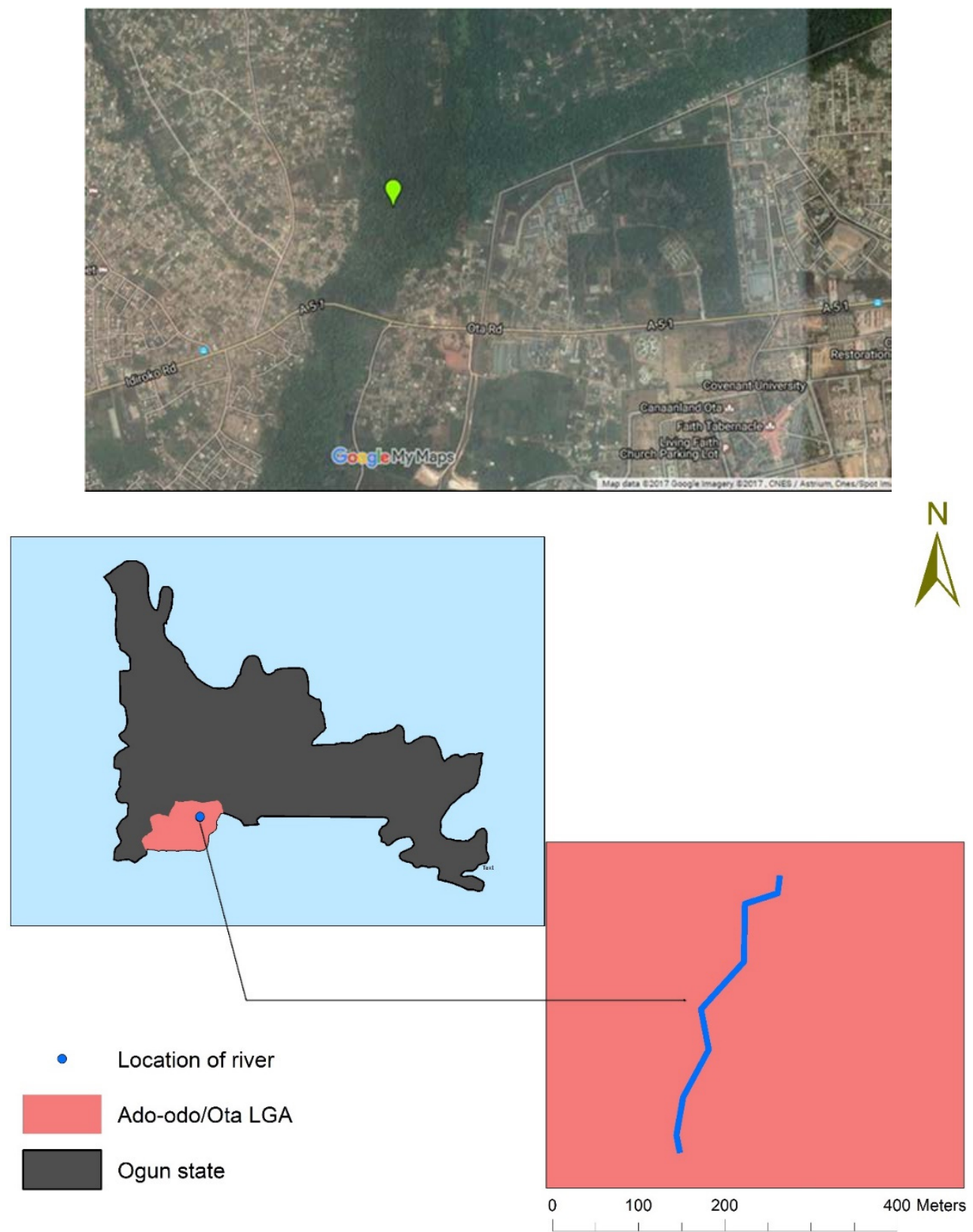

Figure 1: A map showing River Balogun and connecting Rivers within Ota, Ogun State.

method and fixed-time variable distance method [9], [10]. However, so far, the last method aforementioned have been widely used and gives better estimates but does not seem a sustainable approach, with the main challenge of this method is the high cost needed in the purchase of state-of-the-art equipment in large numbers, which is required for tracer data 
collection. Therefore, this has led to limited studies especially in developing countries on the use of tracers or determination of dispersion coefficients. Agunwamba [10] and Moore [11] reported that there is subjectivity in sampling time interval selection. With no scientific explanation from any researcher on the reasons why the time interval was selected. Therefore, this study aims at the determination of the LD of River Balogun that is under pollution treat from dredging activities and industrial pollution, using the constant distance variable time method, at two different sampling time intervals.

\section{METHODS AND MATERIALS}

\subsection{Study area}

The river used for this study is River Balogun with a coordinate of $6^{\circ} 41^{\prime} 6.8^{\prime \prime} \mathrm{N}$ and $3^{\circ} 8^{\prime} 56.37$ "E. The river is a tributary from a popular river called River Atuwara. River Balogun is a major source of water for drinking for most villages surrounding Ota, but suffers pollution threat from industries surrounding it. In addition, the inhabitants surrounding the river have major occupation of fishing, bamboo, cutting and dredging. Besides fishing, the other two activities aforementioned can lead to local pollution. Furthermore, in the dry and wet seasons, the volume of water in the river is enough for boating even when packed full of dredged sand.

\subsection{Field work}

In this study, the constant distance variable time method was employed in the collection of tracer concentration values. $25 \mathrm{~kg}$ of locally made salt (Dangote salt) with $97 \%$ purity level was used as a conservative tracer at each sampling scheme. It was pre-mixed with the River water in parts, in order increase it solubility when poured into the river. Beforehand, the background concentration was obtained before the River was dosed with the tracer. The reason is to know the actual elevation caused by the salt. A $400 \mathrm{~m}$ long portion of the river was marked out for this research using a GPS. After dosing, with the use of a Hanna edge 2020 series Electrical conductivity meter, values were recorded at two different sampling time intervals of 3 minutes and 5 minutes respectively on the same day in the month of January 2017 using the constant distance variable time method otherwise known as the levenspiel and smith approach. This approach involves the monitoring of Electrical conductivity at the outlet at a selected time interval. In this study and in the region where it was conducted, the month of January served as a critical period whereby the stage of the river is low and pollution can be high. In addition, the Electrical conductivity was monitored using a fabricated multi-leveller sampler (Fig. 2). This sampler was designed to obtain the river water samples transversely and vertically simultaneously thereby possibly improving the values of dispersion number, which will be calculated from the average concentration obtained. Thereafter, with the concentration of tracer obtained, the average transverse concentration values were used to determine the dispersion number from eqns (1)-(3) [10]:

$$
d=\frac{1}{8}\left(\sqrt{8 \delta^{2}+1}-1\right)
$$

where $\delta^{2}$ is the area under the normalised concentration-time plot, and given as: 
204 River Basin Management X

$$
\begin{gathered}
\delta^{2}=\frac{1}{-2}\left(\frac{\sum c t^{2}}{\sum c}-\theta\right), \\
\bar{\theta}=\frac{\sum c t}{\sum c}, \\
\bar{\theta}=L / V
\end{gathered}
$$

Also, where $c, t, L, V$ and $\bar{\theta}=$ tracer concentration, time interval, length of the river, velocity, actual (experimental) and hypothetical detention time of tracer. The detention time of tracer helps to predict the travel time of the tracer, and this can be achieved hypothetically or experimentally. Eqns (3) and (4) give the experimental and hypothetical values of the tracer during tracer studies.

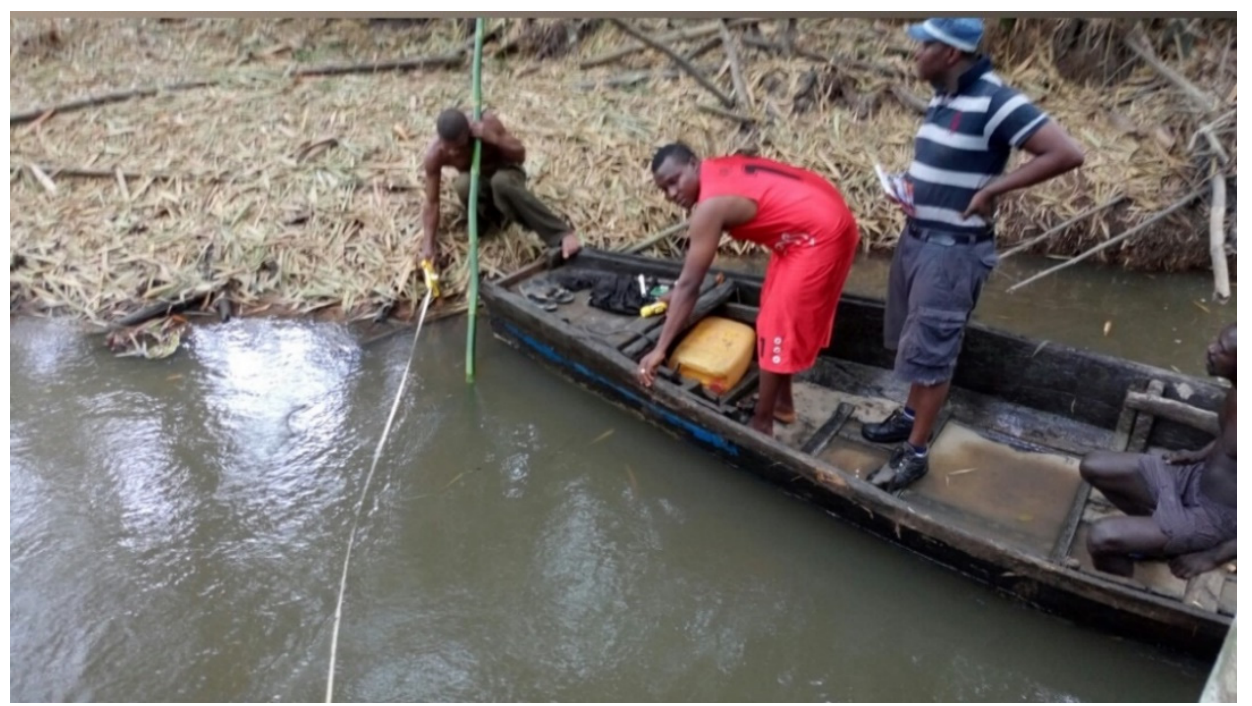

Figure 2: Morphology measurement of one of the sections of River Balogun.

\section{RESULT AND DISCUSSION}

3.1 Effect of sampling interval of 3 mins on the breakthrough curve and dispersion number

Fig. 4 shows the electrical conductivity readings collected from River Balogun and plotted against time. As earlier said, the time interval used for the collection was 3 mins. In addition, the figure reveals the hydraulic characteristics of the River. From the graph, the lowest value of concentration was observed at 9 mins after tracer injection. Surprisingly, the value recorded at that time was $-0.633 \mu \mathrm{s} / \mathrm{cm}$ which resulted from variation in the background 


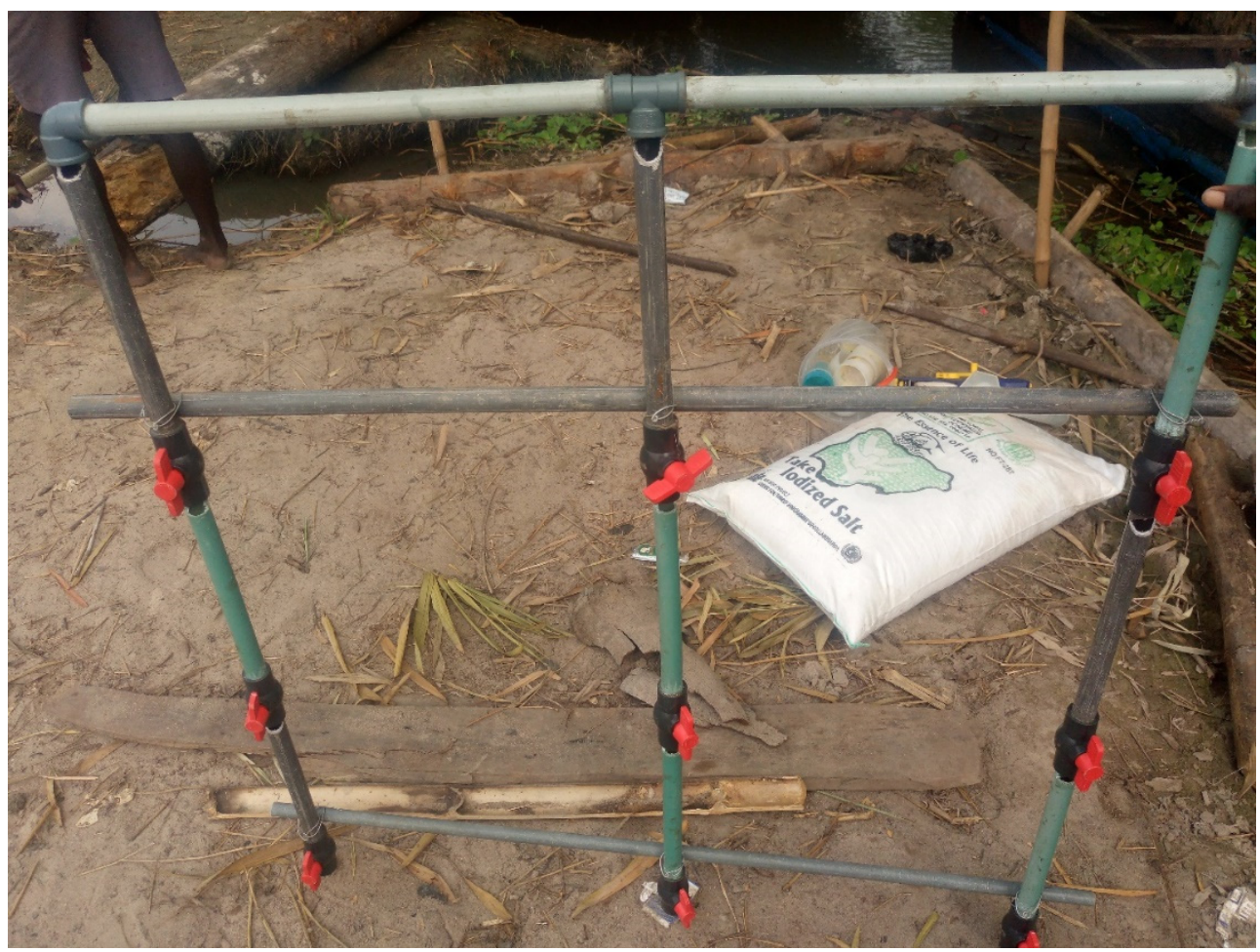

Figure 3: Fabricated multi-leveller sampler for the simultaneous collection of tracer concentrations.

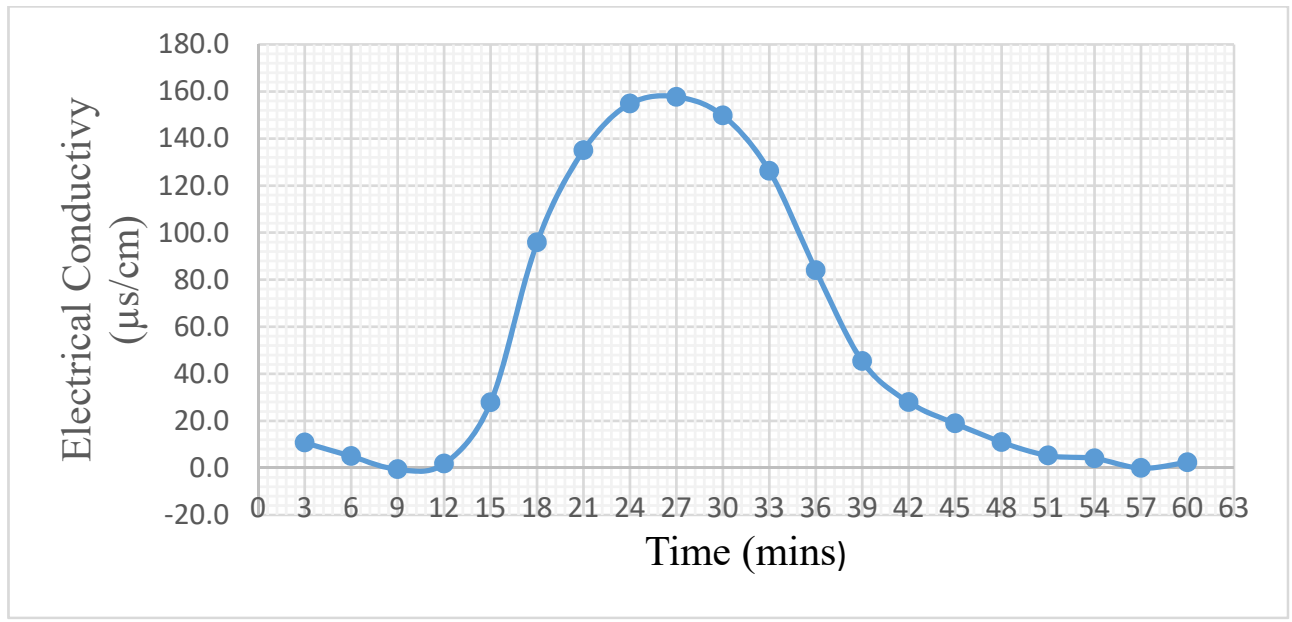

Figure 4: Tracer concentration against time using Levenspiel approach at 3 mins interval. 
concentration value with an average value of $48.5 \mu \mathrm{s} / \mathrm{cm}$ which was adopted as the experimental background concentration. However, it was observed that after monitoring the background concentration of the river for some time, some dataset would still produce negative values. This may be due to variation in geochemical properties of the sections of the channel [12], the contribution of other non-point sources that might have increase the background concentration that or due to probe sensitivity. Although, when was noticed, the probe was calibrated more frequently i.e. after each experimental process, but the variation continued. Conversely, it was observed that the tracer was detected close to the theoretical detention time i.e. $L / V$, from that point onward, consistent increase was observed until it peaked at 27 mins. At 30 mins, a drop in the electrical conductivity was noticed until close to background concentration was obtained at 60 mins of sampling. Furthermore, the graph shows that the long tails usually experienced during sampling is due long sampling time.

\subsection{Effect of sampling interval of 5 mins on the breakthrough curve and dispersion number}

Fig. 5 also reveals the river pattern in terms of the pollutant movement and shape, which from observation is characterised by the sampling scheme adopted. For instance, the shape of the near Gaussian plot in Figs 4 and 5 are not the same; and would certainly affect the value of dispersion number when calculated. The reason being that the dispersion number is a function of the normalised variance produced by the graphs. Again, in this second sampling scheme, the theoretical detention revealed the point of tracer detection. In addition, unlike the first sampling scheme, there was no negative values observed initially; however, values lower than the difference in the chosen background concentration values were recorded with an average value of $51.3 \mu \mathrm{s} / \mathrm{cm}$. This is attributed to the reason earlier mentioned for Fig. 4. On the other hand, the peak value in this sampling scheme was observed at 35 mins as against 27 mins in the first sampling scheme. This may be due to increased number of sampling as well as reduced sampling time interval adopted in the first sampling scheme. Specifically, 20 number of tracer readings were collected in the first experimental scheme, while 13 was collected in the second. This is approximately 1.54 times more in the first scheme. However, it has been mathematical established that the more the points available in a graph, the more its accuracy. Therefore, following this thesis, it is assumed that the dispersion number produced by the first scheme should be more accurate than the second scheme. However, this may not be a realistic interval for researchers and some developing countries who still depend manually for data collection and cannot afford the luxury of data loggers. More explicitly, we imply that selecting the same sampling time ( 3 secs) and any other sampling time lower than this will lead to experimental errors, increase in labour while the intention of reducing sampling time to yield good results would be defeated. Therefore, based on the findings of this study, it is believed that for those researches whereby tracer concentrations were manually or even digitally collected, using any of the known tracer study approaches would have been selected based on the ease of sampling rather than the quest for an accurate value of the dispersion number. Therefore, the result obtained may not be as accurate as expected. Table 1 shows the dispersion number values obtained from the two-different sampling scheme. It reveals that, the dispersion number obtained at $3 \mathrm{mins}$ and that obtained at $5 \mathrm{mins}$ of sampling time interval have a difference of 0.0158 with a factor of 1.74 between it. This shows that sampling time could have a significant effect on the dispersion number generated. However, it is worthy to mention that a variation in the dispersion number can also occur because of the heterogenous nature of river hydrodynamics i.e. Velocity, over time as noticed 
in this study which varied from $0.12 \mathrm{~m} / \mathrm{s}^{2}$ to $0.46 \mathrm{~m} / \mathrm{s}^{2}$ along and within the studied portion of the river and has been noted as one of the limitations of the constant distance variable time approach as captured in the literature [13]-[15].

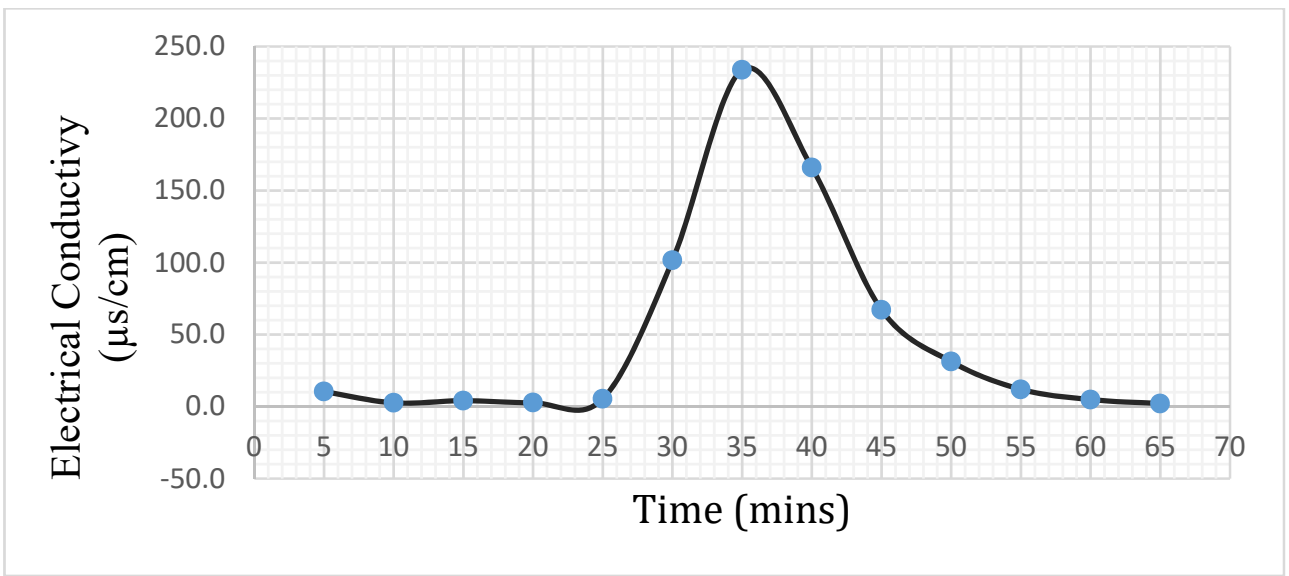

Figure 5: Tracer concentration against time using Levenspiel approach at 5 mins interval.

Table 1: Dispersion number obtained using Levenspiel and Smith Approach at 3 mins and 5 mins respectively.

\begin{tabular}{ccc}
\hline $\begin{array}{c}\text { Dispersion number at } \\
3 \text { mins interval }\end{array}$ & $\begin{array}{c}\text { Dispersion number at } \\
5 \text { mins interval }\end{array}$ & Difference \\
\hline 0.037152 & 0.0214 & 0.0158 \\
\hline
\end{tabular}

\section{CONCLUSION}

Dispersion number is a useful parameter required in the design of intake structures; determination of intake locations as well as the estimation of assimilatory capacities of Rivers. Therefore, a more realistic value is needed for this purpose, to avoid unnecessary error in design of these structures, avoidance of underestimation or overestimation of this dimensionless parameter. This study employed the Levenspiel and Smith approach to conduct tracer studies for the determination of dispersion number of River Balogun, a tributary of River Atuwara in south-west Nigeria at two different sampling time intervals. Tracer studies were conducted using two different sampling time intervals, and it produced different values for dispersion number with the sampling of 3 mins time interval having a dispersion number 1.76 times greater than the dispersion number produced when the time interval was placed at 5 mins. The reason behind this variance was attributed to variation in sampling time interval as well as the river hydrodynamics. Furthermore, this reveals that the subjectivity in sampling interval practised by different researchers during tracer studies no matter the method has a significant role to play as it could contribute to underestimation or overestimation of the dimensionless parameter. Therefore, it is suggested that, more sustainable approaches should be developed that will require the collection of limited tracer concentration data, reduce sampling time interval errors and consider hydrodynamic variations thereby yielding good estimates of dispersion number which could be better than 
the Levenspiel and Smith method adopted in this study. This will promote constant monitoring and encourage developing countries to involve in dispersion studies which hitherto have not been frequently practised.

\section{REFERENCES}

[1] Velísková, Y., Sokáč, M., Halaj, P., Bara. M.K., Dulovičová, R. \& Schügerl, R., Pollutant spreading in a small stream: A case study in Mala Nitra Canal in Slovakia. Environmental Processes, 1, pp. 265-276, 2014.

[2] Velísková, Y., Halaj, P., Sokáč, M. \& Bárek, V., Pollution spread analysis in the Malá Nitra River by using of 1-D model. Acta Horticulturae et Regiotectuare, 17, 2014.

[3] Toprak, Z.F., Hamidi, N., Kisi, O. \& Gerger, R., Modeling dimensionless longitudinal dispersion coefficient in natural streams using artificial intelligence methods. KSCE Journal of Civil Engineering, 18, pp. 718-730, 2013.

[4] Fischer, B.H., The mechanics of dispersion in natural streams. J Hydr Div ASCE, 93, pp. 187-216, 1967.

[5] Fischer, B.H., Dispersion predictions in natural streams. J. Sanit. Eng. Div. ASCE, 94, pp. 927-943, 1968.

[6] Rankinen, K., Lepistö, A. \& Granlund, K., Hydrological application of the INCA model with varying spatial resolution and nitrogen dynamics in a northern river basin. Hydrology and Earth System Sciences, pp. 339-350, 2002.

[7] McIntyre, N., Jackson, B., Wade, A., Butterfield, D. \& Wheater, H., Sensitivity analysis of a catchment-scale nitrogen model. Journal of Hydrology, pp. 71-92, 2005.

[8] Tenebe, I.T., Ogbiye, A.S., Omole, D.O. \& Emenike, P.C., Estimation of longitudinal dispersion co-efficient: A review. Cogent Engineering, 3, pp. 216-244, 2016.

[9] Agunwamba, J.C., Reduction of sampling time in tracer studies. Water Environment Research, 69, pp. 343-349, 1997.

[10] Agunwamba, J.C., Optimal design for dispersion experiments. Water Research, 2361, pp. 4570-4582, 2002.

[11] Moore, R., Introduction to salt dilution gauging for streamflow measurement (Part I). Watershed Management Bulletin, 2004.

[12] Seo, I.W. \& Gadalrah, M.S., Estimating of dispersion coefficient using different forms of lateral velocity distribution. Proceedings of the WEESHE-99 Conference, pp. 217226, 1999.

[13] Perucca, E., Camporeale, C. \& Ridolfi, L., Estimation of the dispersion coefficient in rivers with riparian vegetation. Advances in Water Resources, 32, pp. 78-87, 2009.

[14] Shen, C., Niu, J., Anderson, E.J. \& Phanikumar, M.S., Estimating longitudinal dispersion in rivers using acoustic doppler current profilers. Advances in Water Resources, 33, pp. 615-623, 2010.

[15] Zeng, Y.H. \& Huai, W.X., Estimation of longitudinal dispersion coefficient in rivers. Journal of Hydro-Environment Research, 8, pp. 2-8, 2014. 